\title{
Duplication 8q12: confirmation of a novel recognizable phenotype with duane retraction syndrome and developmental delay
}

\author{
Cyril Amouroux ${ }^{1}$, Marie Vincent ${ }^{2}$, Patricia Blanchet ${ }^{2}$, Jacques Puechberty ${ }^{2,3}$, Anouck Schneider ${ }^{2,3}$, \\ Anne Marie Chaze ${ }^{3}$, Manon Girard ${ }^{3}$, Magali Tournaire ${ }^{3}$, Christian Jorgensen ${ }^{4}$, Denis Morin ${ }^{1}$, Pierre Sarda ${ }^{2}$, \\ Geneviève Lefort ${ }^{2,3}$ and David Geneviève $e^{\star, 2,4}$
}

Duane retraction syndrome (DRS) is a rare congenital strabismus condition with genetic heterogeneity. DRS associated with intellectual disability or developmental delay is observed in several genetic diseases: syndromes such as Goldenhar or Wildervanck syndrome and chromosomal anomalies such as 12q12 deletion. We report on the case of a patient with DRS, developmental delay and particular facial features (horizontal and flared eyebrows, long and smooth philtrum, thin upper lip, full lower lip and full cheeks). We identified a duplication of the long arm of chromosome 8 (8q12) with SNP-array. This is the third case of a patient with common clinical features and $8 \mathrm{q} 12$ duplication described in the literature. The minimal critical region is $1.2 \mathrm{Mb}$ and encompasses four genes: CA8, RAB2, RLBP1L1 and CHD7. To our knowledge, no information is available in the literature regarding pathological effects caused by to overexpression of these genes. However, loss of function of the $\mathrm{CHD7}$ gene leads to CHARGE syndrome, suggesting a possible role of the overexpression of this gene in the phenotype observed in $8 \mathrm{q} 12$ duplication patients. We have observed that patients with $8 q 12$ duplication share a common recognizable phenotype characterized by DRS, developmental delay and facial features. Such data combined to the literature strongly suggest that this entity may define a novel syndrome. We hypothesize that $\mathrm{CHD7}$ duplication is responsible for a part of the features observed in 8q12.2 duplication.

European Journal of Human Genetics (2012) 20, 580-583; doi:10.1038/ejhg.2011.243; published online 18 January 2012

Keywords: duane retraction syndrome; intellectual disability; 8q12 duplication; $C H D 7$ gene; common facial features

\section{INTRODUCTION}

Duane retraction syndrome (DRS) is defined by a congenital strabismus, characterised by horizontal eye movement deficiency (adduction, abduction or both), globe retraction and palpebral fissure narrowing on attempted adduction due to failure of cranial nerve VI with abduction paralysis (in DRS type 1) or adduction paralysis (in DRS type 2 ). DRS is a clinically and genetically heterogeneous condition observed in $\sim 1-4 \%$ of patients with strabismus. ${ }^{1,2}$

DRS can be associated with intellectual disability or developmental delay and is observed in several genetic diseases such as Goldenhar (OMIM 164210) or Wildervanck syndrome (OMIM 314600).

Here, we report on the third patient with DRS, developmental delay, facial features and duplication of the long arm of chromosome 8 (8q12), and suggest the possibility of a novel specific genetic entity with DRS and developmental delay.

\section{PATIENT AND METHODS}

Patient report

The boy was aged 2 years and 3 months when referred to the Genetic Department for developmental delay associated with DRS. He was the first child born to healthy, unrelated parents. Prenatal screening revealed bilateral hydronephrosis at 23 weeks of gestation (WG). The baby was born at 36 WG by a planned Caesarean section for maternal gravidic hypertension. Birth parameters were in the normal range (weight $2120 \mathrm{~g}(-1 \mathrm{SD})$, length $44 \mathrm{~cm}$ $\left(\begin{array}{ll}-1 & \mathrm{SD}\end{array}\right)$, OFC $29.5 \mathrm{~cm}(-1 \mathrm{SD})$ ). He presented hypotonia and feeding difficulties since the first days of life.

At the age of 2 years and 3 months, clinical examination showed normal growth parameters (OFC $-2 \mathrm{SD}$, weight $-1 \mathrm{SD}$, height $-0.5 \mathrm{SD})$. Growth remained in the normal range (at the age of 5 years: OFC $-1.5 \mathrm{SD}$, weight $-1 \mathrm{SD}$, height $-0.5 \mathrm{SD})$.

Psychomotor development was delayed. He sat at 13 months, started walking at 21 months and achieved diurnal toilet training at 5 years. He spoke $\sim 30$ words at 3 years with normal understanding and said his first sentences at 5 years. The patient was very quiet but had mild autistic behaviour troubles such as anxiety and auto- and hetero-aggressivity.

To explore his psychomotor developmental delay, neuropsychological testing was performed at the age of 4 years. The evaluation concluded to the absence of intellectual disability (performance IQ score with WPPSI-III scale was 98).

Physical examination at the age of 4 years revealed facial asymmetry, right plagiocephaly, low posterior hairline, horizontal eyebrows with flaring of the proximal portion, long eyelashes, slight epicanthus, wide protruding ears, wide nasal root, bulbous nasal tip with short columella, long and smooth philtrum, wide mouth, thin upper lip, full lower lip, full cheeks (Figure 1a), high implanted umbilicus, anal anteposition. Ophthalmological examination

${ }^{1}$ Département de Pédiatrie spécialisée, Unité de Néphrologie et Endocrinologie pédiatrique, CHRU Montpellier, Faculté de Médecine de Montpellier-Nîmes, Université Montpellier 1, Montpellier, France; ${ }^{2}$ Département de Génétique Médicale, Centre de Référence Maladies Rares Anomalies du Développement et Syndromes Malformatifs Sud-Languedoc Roussillon, CHRU Montpellier, Faculté de Médecine Université Montpellier 1, France; ${ }^{3}$ Département de Génétique Médicale, Plateforme puce à ADN, CHRU Montpellier, Université Montpellier 1, France; ${ }^{4}$ Unité Inserm U844, Institut des Neurosciences de Montpellier, Montpellier, France

*Correspondence: Dr D Geneviève, Département de Génétique Médicale, Hôpital Arnaud de Villeneuve, CHRU de Montpellier, 371 Avenue du Doyen G, Giraud 34000 , Montpellier, France. Tel: +33 04673365 64; Fax: +33 04673360 52; E-mail: d-genevieve@chu-montpellier.fr

Received 28 April 2011; revised 26 September 2011; accepted 11 October 2011; published online 18 January 2012 
revealed mild esotropia in primary position of the left eye (Figure 1a). Ocular motility examination was performed, and concluded to normal motility of the right eye and defective abduction of the left eye. Globe retraction and palpebral fissure narrowing on attempted adduction was also observed. Ophthalmological investigation concluded to DRS type 1 of the left eye.

ENT investigation concluded to normal hearing. Kidney ultrasound revealed bilateral hypoplasia of the lower part of the kidney and bilateral pyelectasis. Skeletal X-ray showed hypoplasia of the left-sided rib and a small mandible. Heart ultrasound was normal.

\section{Cytogenetic investigations}

Karyotype was established using standard procedures for cell culture and chromosome banding.

Array genomic hybridization analysis was performed for the child and his parents. DNA was extracted from whole blood using the QIAamp DNA Blood Maxi Kit (Qiagen, Courtaboeuf, France) according to the supplier's protocol. Microarray analysis was performed using Genome-Wide Human SNP Array 6.0 (Affymetrix, High Wycombe, UK) according to the manufacturer's instructions. The Array was analyzed using the Scanner 3000 7G and Command Console Software (AGCC; Affymetrix). Results were processed and visualized by Genotyping Console software 4.0 and Visiopuce (http://www.renapa.univ-montp1.fr/ spip.php?article96\&lang=fr) a French academic database used for CNV analysis in combination with other academic databases (DECIPHER and ECARUCA). DNA sequence information refers to the public UCSC database GRCh37 (hg19). FISH experiments using probes were performed according to standard procedures. Probes RP11-51L11 (8q12.1), RP11-33I11 (8q12.2; overlapping CHD7 gene) and RP11-763K01 (8q12.3) were obtained from Human $32 \mathrm{~K}$ clone set. ${ }^{3}$ Plasmid $\alpha$-centromeric-specific pZ8.4 probe, used as a control, was kindly provided by Dr M Rocchi (University of Bari, Bari, Italy). Probes were cultured in LB medium with an appropriate antibiotic selection. Probe DNA was extracted from the cell pellet using the QIAamp Plasmid Midi Kit (Qiagen) according to the supplier's protocol.

\section{RESULTS}

Blood chromosomes from the patient and his parents were normal. SNP-array analysis and FISH of the parents were normal whereas SNParray analysis of the affected child revealed a duplication of the long arm of chromosome 8 of $\sim 3.85 \mathrm{Mb}$ (arr 8q12.1q12.3(6021974664072039)x3 dn (hg19)). The duplication was confirmed using the BAC probe RP11-33I11 encompassing the CHD7 gene (Figure 1b, white arrow) and the BAC probes RP11-51L11 and RP11-763K01. However, we failed to determine whether the duplication was inverted or in tandem.

\section{DISCUSSION}

DRS is observed as an isolated feature or in association with other features such as developmental delay or malformations. According to the London medical database the association of DRS with developmental delay as been observed in few patients in around nine entities including six syndromes (ie, Bardet Biedl syndrome (OMIM 209900), ${ }^{4}$ Blepharophimosis Ptosis Epicanthus Inversus Syndrome(OMIM $110100),{ }^{5}$ Goldenhar syndrome (OMIM 164210), ${ }^{6}$ Moebius syndrome (OMIM 157900), ${ }^{7}$ Wildervanck syndrome (OMIM 314600) ${ }^{8}$ and Athabascan brainstem dysgenesis syndrome (OMIM 601536) ${ }^{9}$ ), foetal alcohol syndrome, ${ }^{10}$ and several chromosomal anomalies namely 12q12 microdeletion ${ }^{11}$ and 20q13.13-13.2 deletion. Clinical features associated with the 20q13.13-13.2 deletion are probably due to a contiguous gene deletion encompassing the SALL4 gene responsible for Okihiro syndrome (DRS, renal deficiency and limb features $)^{12}$ and other genes responsible for intellectual disability.

Several $8 \mathrm{q}$ anomalies have been observed in patients with DRS namely $8 \mathrm{q} 12.2-\mathrm{q} 21.2$ deletion in one patient, ${ }^{13} 8 \mathrm{q} 13$ deletion in one

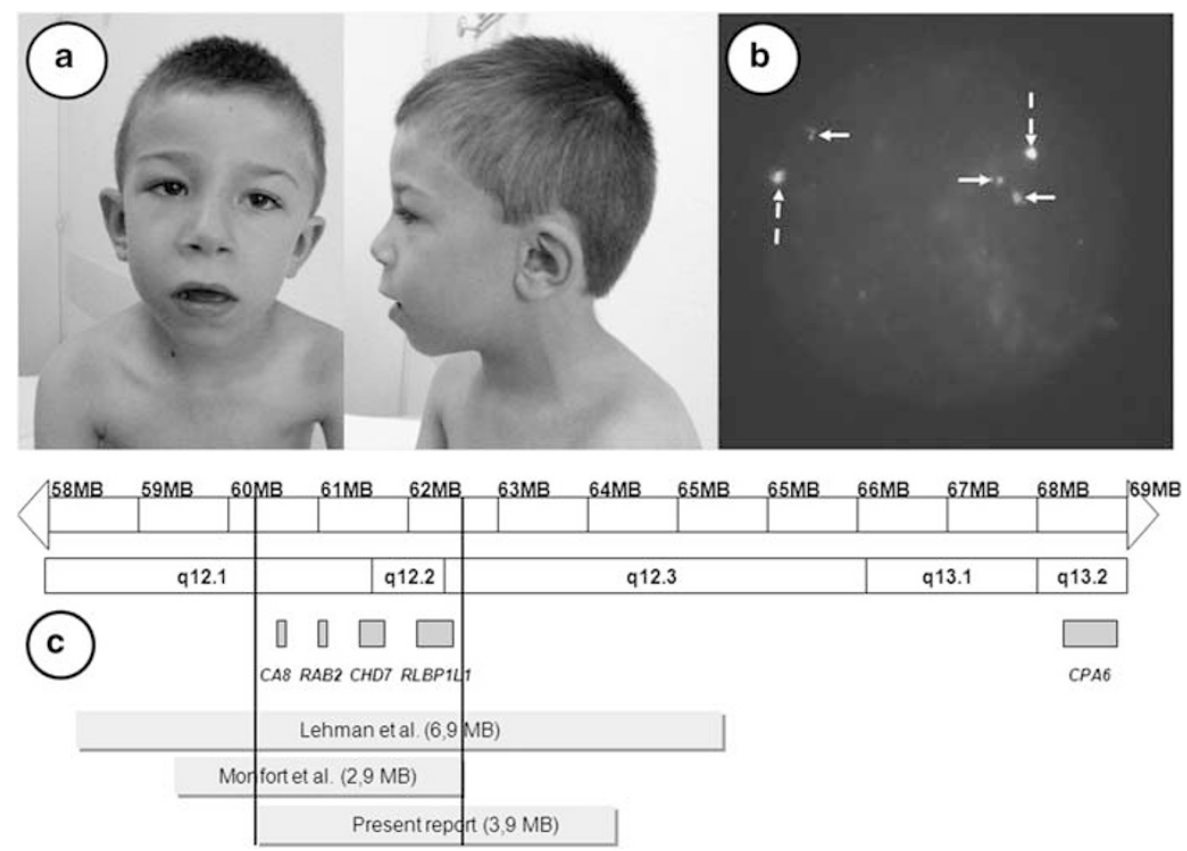

Figure 1 (a) Front and lateral view of the patient at the age of 4 and a half years. Note esotropia of the left eye, flaring of the proximal part of the eyebrows, bulbous tip of the nose with large nostrils, wide mouth with long philtrum, eversion of the lower lip and full cheeks, (b) FISH results from the patient, revealing 2 green spots (indicated by doted and vertical arrows) corresponding to the centromeric control probe (pZ8.4) and 3 red spots (indicated by full and horizontal arrows) corresponding to 8q12.2 region (probe RP11-33I11 encompassing the CHD7 gene), and (c) schematic representation of the three $8 \mathrm{q} 12$ duplications reported in the literature. Note that the minimal critical region (delineated by the black vertical bars) contains only 4 genes namely $C A 8$, RAB2, RLBP1L1 and CHD7. Note also the distance between the minimal critical region and the CPA6 gene corresponding to the DRS locus located at 8q13.2. The color reproduction of this figure is available at the European Journal of Human Genetics online. 
patient, ${ }^{14} 8 \mathrm{q} 13.2$ translocation involving the CPA6 gene in one patient $^{15}$ and $8 \mathrm{q} 12.2$ duplication in two patients. ${ }^{16,17}$

We report on the third patient with an $8 \mathrm{q} 12.2$ duplication $^{16,17}$ and identify common clinical features in an attempt to delineate a new recognizable phenotype.

The clinical similarities between the three patients with 8q12 duplication are summarized in Table 1. Common features in these patients were neurodevelopmental delay (neonatal hypotonia, delayed sitting, walking, toilet training) with language delay, DRS and facial features (horizontal, flared medial eyebrows becoming thinner laterally, long and smooth philtrum, bulbous tip of the nose, wide Cupid's bow, thin upper lip and full lower lip and full cheeks). Heart and kidney malformations as well as deafness were inconstant but seem to be features of this novel syndrome.

The present reported patient has a de novo $3.85 \mathrm{Mb}$ duplication encompassing eight genes. The size of the minimal critical region observed in the three patients (Figure 1c) is $\sim 1.2 \mathrm{Mb}$, and is located at 8q12.2. This region encompasses only four genes, namely, carbonic anhydrase VIII (CA8), ras-related protein RAB2B (RAB2), clavesin 1 (CLVS1) and chromodomain helicase DNA-binding protein 7 (CHD7) genes.

In an attempt to determine which genes (or combination of genes) are responsible for the phenotype observed in the three patients, we considered the known functions of the genes located in the minimal critical region.

The CA8 gene encodes for a protein that modulates intracellular calcium signalling. This protein is highly expressed in cerebellum Purkinje cells. ${ }^{18}$ Homozygous loss of function mutations of the CA8 gene have been found to be associated with mild intellectual disability and ataxia with quadrupedal gait (OMIN 613227). ${ }^{19}$ To the best of our knowledge, no germinal gain of function of the $C A 8$ gene has been described so far.
The $R A B 2 B$ gene encodes for a GTP-binding protein that controls vesicular fusion and trafficking in Golgi apparatus in eukaryotic cells. ${ }^{20}$

The clavesin 1 gene (CLVS1, also named retinaldehyde-binding protein 1-like 1, RLBP1L1) belongs to the clavesin family, which is expressed exclusively in neurons, and appears to provide neuronspecific regulation of late endosome/lysosome morphology. ${ }^{21}$ To date no gain of function of this gene has been described in the literature.

The CHD7 gene encodes for a protein involved in the development of the embryo by modifying chromatin organization and the regulation of transcription. ${ }^{22}$ The protein products of the CHD7 gene can modulate genes in either the positive or negative direction, suggesting that gene dosage of the CHD7 gene may have an effect on the regulated genes. ${ }^{23}$ To our knowledge, no information is available in the literature regarding pathological effects secondary to overexpression of the CHD7 gene. However, loss of function of this gene leads to CHARGE syndrome ${ }^{24}$ possibly by dysregulation of tissue-specific gene expression. It is interesting to note that 8q12.2 duplication and CHARGE syndrome involve several similar anatomic regions namely brain, eyes, ears, heart and genitourinary tractus even if the clinical manifestations observed in these two genetic conditions are different. It is tempting to speculate that three copies of this gene may be responsible for a part of the phenotype observed in the patients with $8 \mathrm{q} 12.2$ duplication.

Moreover, two loci on chromosome 8 are known to be associated with DRS. One of these is located on the long arm of chromosome 8 at the 8q13.2 locus, between genomic markers SHGC37325 and WI4901, $6 \mathrm{Mb}$ from the common duplicated region described in this report (Figure 1c). This locus encompasses the CPA6 gene, which has been reported to be deleted ${ }^{15}$ or interrupted ${ }^{25}$ in patients with DRS. However, a formal role of CPA6 in abducens development is questionable regarding experimental Zebrafish data. ${ }^{26}$ The very long

Table 1 Comparison of the three children with $8 q 12$ duplication, inspired by Lehman et al 17

\begin{tabular}{|c|c|c|c|}
\hline Patient reported & Monfort et al 16 & Lehman et al 17 & Present report \\
\hline Neonatal hypotonia & + & + & + \\
\hline OFC & NR & Microcephaly & Normal \\
\hline Facial features & + & + & + \\
\hline Flaring of eyebrows & + & + & + \\
\hline Horizontal eyebrows & + & + & + \\
\hline Wide nasal root & + & NR & + \\
\hline Bulbous nasal tip & + & NR & + \\
\hline Full cheeks & + & NR & + \\
\hline Long philtrum & + & NR & + \\
\hline Wide mouth & NR & NR & + \\
\hline Full lower lip & + & NR & + \\
\hline Duane retraction syndrome & $+($ Undefined $)$ & $+($ Type 1$)$ & + (Type 1) \\
\hline Deafness & + & + (With Mondini dysplasia) & - \\
\hline Motor development delay & + & + & + \\
\hline Language delay & NR & + & + \\
\hline Intellectual disability & + & NR & - \\
\hline Behaviour & Hyperactivity & NR & Autistic features \\
\hline Feeding difficulties & NR & + & + \\
\hline Heart malformation & PS, VSD & ASD, VSD & - \\
\hline Renal features & NR & Vesicular reflux & Kidney hypoplasia \\
\hline Limbs & NR & Brachydactyly & Normal \\
\hline Constipation & NR & + & + \\
\hline
\end{tabular}

Abbreviations: ASD, atrial septal defect; NR, not reported; OFC, occipito-frontal circumference; PS, pulmonary stenosis; VSD, ventricular septal defect. 
distance separating this locus and the 8q12.2 duplication region observed in our patients makes unlikely a link between this locus and the DRS observed in the three patients with $8 \mathrm{q} 12.2$ duplication. However, we cannot rule out the existence of a long-range regulatory element of the CPA6 gene in $8 \mathrm{q} 12$.

We believe that patients with $8 \mathrm{q} 12.2$ duplication share a common novel syndrome with a recognizable phenotype characterized by DRS, developmental delay, facial features and variable heart and kidney malformations. We hypothesize that $C H D 7$ duplication is responsible for a part of the features observed in 8q12.2 duplication. Future studies aimed at investigating for duplication of the CHD7 gene in patients with DRS, developmental delay, similar facial features and normal chromosomal studies are necessary to confirm our hypothesis.

\section{CONFLICT OF INTEREST}

The authors declare no conflict of interest.

\section{ACKNOWLEDGEMENTS}

We thank the patient and the family members for their support. Part of this work was supported by a research programme (Programme Hospitalier de Recherche Clinique Régional Languedoc-Roussillon) and by the Direction Générale de l'Organisation des Soins (DGOS). Affymetrix microarrays were processed in the Microarray Core Facility of the Institute of Research on Biotherapy, CHRU-INSERM-UM1 Montpellier, http://irb.chu-montpellier.fr/.

1 Ahluwalia BK, Gupta NC, Goel SR, Khurana AK: Study of Duane's retraction syndrome. Acta Ophthalmologica 1988; 66: 728-730.

2 DeRespinis PA, Caputo AR, Wagner RS, Guo S: Duane's retraction syndrome. Surv Ophthalmol 1993; 38: 257-288.

3 Krzywinski M, Bosdet I, Smailus D et al: A set of BAC clones spanning the human genome. Nucleic Acids Res 2004; 12: 3651-3660.

4 Jethani J, Parija S, Shetty S, Vijayalakshmi P: Atypical association of Duane retraction syndrome and Bardet Biedl syndrome. Indian J Ophthalmol 2007; 55: 139-141.

5 Vincent AL, Watkins WJ, Sloan BH, Shelling AN: Blepharophimosis and bilateral Duane syndrome associated with a FOXL2 mutation. Clin Genet 2005; 68: 520-523.

6 Tillman O, Kaiser HJ, Killer HE: Pseudotumor cerebri in a patient with Goldenhar's and Duane's syndromes. Ophthalmologica 2002; 216: 296-299.

7 Verzijl HT, van der Zwaag B, Lammens M, ten Donkelaar HJ, Padberg GW: The neuropathology of hereditary congenital facial palsy vs Möbius syndrome. Neurology 2005; 64: 649-653.
8 Cremers CWRJ, Hoogland GA, Kuypers W: Hearing loss in the cervico-oculo-acoustic (Wildervanck) syndrome. Arch Otolaryng 1984; 110: 54-57.

9 Tischfield MA, Bosley TM, Salih MAM et al: Homozygous HOXA1 mutations disrupt human brainstem, inner ear, cardiovascular and cognitive development. Nature Genet 2005; 37: 1035-1037

10 Holzman AE, Chrousos GA, Kozma C, Traboulsi El: Duane's retraction syndrome in the fetal alcohol syndrome. Am J Ophthalmol 1990; 110: 565-566.

11 Failla $\mathrm{P}$, Romano $\mathrm{C}$, Reitano $\mathrm{S}$ et al: $12 \mathrm{q} 12$ deletion: a new patient contributing to genotype-phenotype correlation. Am J Med Genet Part A 2008; 146A: 1354-1357.

12 Borozdin W, Graham Jr JM, Böhm D et al: Multigene deletion on chromosome 20q13.13-q13.2 including SALL4 result in an expanded phenotype of Okihiro syndrome plus developmental delay. Hum Mut 2007; 28: 830-840.

13 Vincent $\mathrm{C}$, Kalatzis V, Compain S et al: A proposed new contiguous gene syndrome on $8 \mathrm{q}$ consists of Branchio-Oto-Renal (BOR) syndrome, Duane syndrome, a dominant form of hydrocephalus and trapeze aplasia; implications for the mapping of the BOR gene. Hum Mol Genet 1994; 3: 1859-1866.

14 Calabrese G, Stuppia L, Morizio E et al: Detection of an insertion deletion of region $8 q 132 q 21.2$ in a patient with Duane syndrome: implications for mapping and cloning a Duane gene. Eur J Hum Genet 1998; 6: 187-196.

15 Pizzuti A, Calabrese G, Bozzali M et al: A peptidase gene in chromosome $8 \mathrm{q}$ is disrupted by a balanced translocation in a Duane syndrome patient. Invest Ophthalmol 2002; 43: 3609-3612.

16 Monfort S, Rosello M, Orellana C et al: Detection of known and novel genomic rearrangements by array based comparative genomic hybridisation: deletion of ZNF533 and duplication of CHARGE syndrome genes. J Med Genet 2008; 45: 432-437.

17 Lehman AM, Friedman JM, Chai D et al: A characteristic syndrome associated with microduplication of 8q12, inclusive of CHD7. Eur J Med Genet 2009; 52: 436-439.

18 Hirota J, Ando H, Hamada K, Mikoshiba K: Carbonic anhydrase-related protein is a novel binding protein for inositol 1,4,5-trisphosphate receptor type 1 . Biochem $J$ 2003; 372: 435-441.

19 Türkmen S, Guo G, Garshasbi M et al: CA8 mutations cause a novel syndrome characterized by ataxia and mild intellectual disability with predisposition to quadrupedal gait. PLoS Genet 2009; 5: e1000487.

$20 \mathrm{NiX}, \mathrm{Ma}$ Y, Cheng $\mathrm{H}$ et al: Molecular cloning and characterization of a novel human Rab (Rab2B) gene. J Hum Genet 2002; 47: 548-551.

21 Katoh Y, Ritter B, Gaffry T, Blondeau F, Honing S, McPherson PS: The clavesin family, neuron-specific lipid- and clathrin-binding Sec14 proteins regulating lysosomal morphology. J Biol Chem 2009; 284: 27646-27654.

22 Vissers LE, Van Ravenswaaij CM, Admiraal R et al: Mutations in a new member of the chromodomain gene family cause CHARGE syndrome. Nat Genet; 2004; 36: 955-957.

23 Schnetz MP, Handoko L, Akhtar-Zaidi B et al: CHD7 targets active gene enhancer elements to modulate ES cell-specific gene expression. PLoS Genet 2010; 6: e1001023.

24 Jongmans MC, Admiraal RJ, Van der Donk KP et al: CHARGE syndrome: the phenotypic spectrum of mutations in the CHD7 gene. J Med Genet 2006; 43: 306-314.

25 Calabrese G, Telvi L, Capodiferro F et al: Narrowing the Duane syndrome critical region at chromosome 8q13 down to $40 \mathrm{~kb}$. Eur J Hum Genet 2000; 8: 319-324.

26 Lyons PJ, Ma LH, Baker R, Fricker LD: Carboxypeptidase A6 in zebrafish development and implications for VIth cranial nerve pathfinding. PLoS One 2010; 5: e12967. 